It is often used to describe the simple exercise of collecting figures, e.g. the number of DSH admissions or the percentage of GPs who prefer their patients having depots given at a hospital clinic. These are, however, examples of surveys. My computer thesaurus informs me of other words which could be exchanged for audit: study, investigation, poll, examination, assessment, analysis.

Unless the information collected results in standards being set, guidelines being produced or some sort of structured change implemented, it cannot be called audit. Research is often used synonymously with audit, but the same rules apply. A further important difference between research and audit is the condition of carrying out a re-audit, in order to determine whether practice has improved.

I, and my audit colleagues, would be grateful if you could encourage the proper use of the word.

PAUL KIRBY, Medical Audit Officer, General Psychiatry, St James's University Hospital, Leeds LS9 7TF

(Point noted-Ed.)

\section{Abuse of human rights in Rwanda}

Sir: No-one will fail to have been appalled by the news coming from Rwanda in the last three months. Shock and a sense of impotence to stem this wave of genocide prevails.

Drs Peter Hall and Andrew Carney, representing Physicians for Human Rights UK (PHR UK), were interviewed on BBC News on 15 July while investigating abuses in the remains of a Kigali psychiatric hospital. Worse than any Bedlam, those patients surviving a military attack were witnessed to be at the mercy of the ignorance and fear of the non-medical refugees seeking some asylum there.

Everyone working in mental health services will have an understanding of the prejudices about psychiatric ill health, but few I am sure would have suspected how depraved some people's behaviour could have become towards those most vulnerable. This is, however, only one example of an horrific catalogue of atrocities committed en masse. Perhaps the only hope we can have that this does not recur is to attempt to understand some of the driving forces in initiating and condoning these murders, as well as the psychological effects on survivors, witnesses and perpetrators. This is one of the aims for the members of the PHR team currently in Rwanda.

MORAG L. ROBERTSON, Worcester Royal Infirmary NHS Trust, Newtown Branch, Newtown Road, Worcester WR5 1JG

\section{An open letter to the Secretary of State for Health}

The Mental Health Act of 1983 arose out of the anti-psychiatry movement which was prevalent before that date. This involved the specific denigration of psychiatrists, particularly consultant psychiatrists.

This I think was reflected within the Mental Health Act 1983 from which came the Code of Practice. On page 3 of the Code of Practice, the initial letters of Approved Social Worker are in upper case, but when doctors are mentioned, even though they are specifically mentioned within the terms of the Mental Health Act, their name does not start in upper case. This may be a mistake, but on pages 24 and 25 the Second Doctor is not in upper case although ASW is and Managers are in upper case. On page 25, regarding the Responsible Medical Officer, an extremely significant person within the terms of the Mental Health Act, neither the full name starts in upper case nor does the abbreviation rmo. In the same sentence Managers start in upper case and the patient's rmo is in lower case.

It is quite clear that this is not a mistake but is deliberately intended and is a symbolic devaluation of the role and person of the Responsible Medical Officer in particular and doctors in general.

I would be grateful for your comments and even more grateful if the next edition of this Code of Practice could be suitably amended so that due respect is paid to the professionals mentioned.

DAvid MARJOT, 85 The Avenue, Sunbury on Thames, TW16 $5 \mathrm{HZ}$ 